\title{
Convención Interamericana contra el Terrorismo: Entre la involución de las garantías y la desprotección de los derechos humanos
}

\author{
Myrna Villegas Díaz \\ Profesora de Criminología \\ Universidad de Chile
}

\section{Introducción}

Tras el atentado a edificios emblemáticos de la defensa y economía norteamericanas, la comunidad internacional y los Estados han bregado por una mayor efectividad y eficiencia en la lucha contra el terrorismo. Es altamente preocupante que tras la hipertrofia legislativa a la que hemos asistido desde septiembre de 2001, la tendencia siga siendo la proliferación de una normativa de excepción en su tratamiento jurídico. Parece ser que se olvida que la solución al terrorismo no se agota en el plano jurídico internacional o nacional, parece ser que se olvida que el terrorismo es, ante todo, un problema político y social. Un fenómeno que no es sino consecuencia de la lucha antagónica que se da en nuestras sociedades.

Organismos de derechos humanos, juristas e investigadores han denunciado los efectos de la normativa de excepción, por su carácter violatorio a los derechos fundamentales y a los derechos humanos, efectiva o potencialmente. Efectivamente cuando se alteran las normas comunes en el tratamiento de la criminalidad, o se infringen normas de derecho internacional de los derechos humanos. Potencialmente cuando la legislación deja una puerta abierta a los abusos y arbitrariedades por parte de la autoridad.

Esta forma de legislar se ampara en la necesidad de dar una respuesta legislativa rápida y eficaz a una opinión pública que, presa de una verdadera histeria colectiva tras cada atentado irracional, e influida por las campañas antiterroristas de los medios de comunicación, exige mayor represión. A ello cabe añadir el papel que ha jugado el proceso de globalización, que, tendiendo a una internacionalización de la legislación, abre una puerta para que se institucionalice la normativa de emergencia o excepción. Los últimos acuerdos y convenios internacionales $^{1}$ han servido como caballo de batalla en las legislaciones nacionales para aumentar

* Myrna Villegas Díaz es abogada chilena y Dra. en Derecho por la Universidad de Salamanca, España especializada en el tratamiento jurídico del terrorismo. Imparte clases en las Facultades de Derecho de la Universidad de Chile y Universidad Arcis.

1 La respuesta, en Europa, ha adoptado un carácter regional homogéneo, concretándose en acuerdos internacionales tales como: Convenio Europeo para la represión del terrorismo (1977), al Acuerdo de Schengen (1985), el Convenio de Aplicación del Acuerdo de Schengen (1990), y al Tratado de la Maastricht, TUE (1997). Tras los atentados de 11 de septiembre de 
facultades a la policía, penalizar actos preparatorios, castigar la colaboración entre otros, en suma, para alejarse cada vez más de lo que son los puntos de partida en el derecho penal: su carácter de última ratio y el respeto a los derechos fundamentales. Se observa con preocupación que el derecho penal y el derecho internacional se convierten así en instrumentos legitimadores de determinadas medidas represivas que afectan potencialmente a todas las personas, porque el control social que se ejerce sobre el terrorismo normalmente se extiende a sectores o grupos ajenos a él.

No se está justificando el terrorismo, sino simplemente haciendo un llamado de atención: si el terrorismo es esencialmente contrario a los derechos humanos, si su actividad irracional genera efectos traumáticos en una sociedad, cabe concluir que la comunidad internacional y los Estados, en su respuesta legislativa, han de respetar tales derechos, garantizarlos y hacerlos cumplir. Este y no otro es el objetivo que ha de considerarse en la prevención y sanción del terrorismo.

Hoy día vemos cómo la normativa internacional apunta a otro objetivo: destruir las bases económicas y financieras del terrorismo, y a tales efectos se han dictado un sinnúmero de medidas tanto por parte de Naciones Unidas como por parte de la CEE.

Una lucha a toda costa contra el terrorismo lleva el peligro intrínseco de transformar a nuestros países en Estados Policiales, impulsores de políticas penales de orden público que merman la convivencia democrática conduciéndonos a un proceso de fascistización de los Estados. En tal proceso se hace primar la razón de Estado por sobre la razón jurídica respetuosa de los derechos fundamentales. Se retorna a los viejos criterios de la seguridad nacional, como objeto central de protección, posibilitando nuevamente prácticas atentatorias contra los derechos humanos, práctica de la que los países latinoamericanos han sido testigos bajo el terrorismo de Estado.

En América Latina la respuesta legislativa frente al terrorismo, desde la década de los 90 y hasta antes de los atentados de 11 de septiembre de 2001, había sido general. La cooperación interestatal se ha centrado fundamentalmente en convenios generales, bilaterales o multilaterales (materias penales y judiciales), así como de tratamiento policial y de ejecución penal. Por otra parte, la condena al terrorismo aparece en todas las cumbres iberoamericanas y resoluciones de la OEA sin carácter vinculante, como lo fueron las adoptadas en la Conferencia Especializada Interamericana sobre Terrorismo, celebrada en Lima (23 y 26 de abril de 1996) ${ }^{2}$. Más tarde se

2001, cabe destacar la reunión extraordinaria de la UE, de 21 de septiembre de 2001, en la que se calificó al terrorismo como un verdadero reto para el mundo y para Europa, y por tanto la lucha contra él sería un objetivo prioritario, siendo una necesidad urgente el ataque a las bases económicas y financieras de las organizaciones terroristas que operan en Europa. Así en el reglamento aprobado en dicha reunión (Documento 50IPC0521), se consideran, entre otros, el decomiso y confiscación de los bienes de las organizaciones sospechosas de estar vinculadas al terrorismo, y la congelación de capitales. Paralelamente se han aunado esfuerzos en torno a reforzar la cooperación judicial y policial. En el primer caso, nos encontramos con nuevas medidas tendentes a agilizar los procesos de extradición (extradiciones automáticas), el reconocimiento de sentencias judiciales extranjeras abriendo el camino ancho a la extraterritorialidad en materia penal, la creación de una Unidad Judicial Antiterrorista (Eurojust), que tiene vinculación directa con Europol, que entraría en vigor durante el mes de enero de 2002. En el segundo caso, cooperación policial, nos encontramos con nuevas medidas de vigilancia y control en aeropuertos, $y$ en todos aquellos lugares considerados posibles objetivos del terrorismo, entre otros.

2 Dicha conferencia nace en cumplimiento a la Resolución de la Asamblea General AG/RES 1350 (XXVO/95). Véase OEA Asamblea General, Actas y Documentos,Vol I.Vigésimo quinto péríodo ordinario de sesiones, Montrouis, Haití, del 5 al 9 de junio de 1995. OEA/Ser.P/XXV.O2, 28 agosto 1995. 
aprobarían y adoptarían la "Declaración de Lima para Prevenir, Combatir y Eliminar el Terrorismo" y el "Plan de Acción sobre cooperación hemisférica para Prevenir, Combatir y Eliminar el Terrorismo". En ellos se plantea la posibilidad de que los gobiernos de los Estados americanos promuevan acuerdos bilaterales y subregionales dirigidos a enjuiciar y penalizar a los que cometen actos terroristas, además de aunar esfuerzos en torno al establecimiento de un sistema de información y control respecto de tales conductas ${ }^{3}$.

A partir de la Resolución $N^{o} 1.373$ de 28 septiembre de 2001, dictada por el Consejo de Seguridad de Naciones Unidas, la cooperación internacional tendería a complementarse, instando a los Estados a que adopten medidas para prevenir y reprimir en sus territorios, por todos los medios legales, la financiación y preparación de actos de terrorismo. Dicha directiva está siendo cumplida por los Estados.

Chile no ha sido ajeno a esta transformación, y aunque no ha modificado la Ley 18.314, sobre conductas terroristas en los últimos diez años, por Decreto $N^{\circ} 488$ del Ministerio de Relaciones Exteriores (13 Nov. 2001) se ordena dar cumplimiento a la Resolución $\mathrm{N}^{\circ} 1.373$ de 28 septiembre de 2001, ya individualizada. Del mismo modo, y mediante Decreto $N^{0} 519$ (6 de feb. 2002), ha promulgado el Convenio Internacional para la Represión de los Atentados Terroristas Cometidos con Bombas, aprobado en Nueva York el 15 de diciembre de 1997.

La última acción conjunta emprendida por los Estados ha sido la recientemente aprobada Convención Interamericana contra el Terrorismo ${ }^{4}$ (en adelante CICT), de 3 de junio de 2002, nacida en el seno de la Organización de Estados Americanos ${ }^{5}$. Como se intentará demostrar a continuación, siguiendo los lineamientos político criminales impuestos por norteamericanos y europeos, parece ser uno de los más paradigmáticos ejemplos de insuficiencias en relación al derecho penal de garantías.

\section{Orientación general de la CICT}

De acuerdo a su preámbulo, la Convención Interamericana tiene por objeto el fortalecimiento de la cooperación hemisférica para prevenir, combatir y eliminar el terrorismo. Del conjunto del articulado se desprende que toma como objetivo central el ataque a las bases económicas y financieras del terrorismo, instando a los Estados a establecer un régimen jurídico y administrativo en tal sentido.

Dos aspectos interesa resaltar:

1. El "concepto de terrorismo" y el trasfondo de esta estrategia de ataque a las bases económicas del terrorismo.

3 Villegas Diaz, Myrna. Terrorismo: Un problena de Estado. Tratamiento juridico en la legislación comparada. Especial referencia a los delitos de terrorismo en las legislaciones de Chile y España. Tesis doctoral, Universidad de Salamanca, España, 2001,Vol. I, p. 367.

4 El Proyecto de la Convención Interamericana contra el Terrorismo fue adoptado por el grupo de trabajo en su reunión celebrada el 21 de marzo de 2002, y fue discutido en julio de 2002.

5 Trigésimo Segundo Periodo Ordinario de sesiones. OEA/Ser. P, 2 'de junio de 2002. Bridgetown, Barbados, 3 de junio de 2002. 
2. La forma en que las medidas derivadas de tal planteamiento está afectando a la normativa internacional de los derechos humanos, y atentando contra principios jurídicos básicos de los Estados democráticos.

\section{II.1. El concepto de terrorismo}

El concepto de terrorismo ha sido tradicionalmente fuente de polémica en los diversos sectores. No ha existido hasta ahora un aunamiento de criterios ni en la legislación ni en la doctrina en torno al mismo. Tras los atentados de 11 de septiembre, este "concepto" vuelve a ponerse en el centro de la discusión. La Unión Europea destina sus esfuerzos hacia la fijación de un concepto común de terrorismo cuya concreción sería la adopción de legislaciones similares en cada uno de los países miembros. Los Estados Unidos, por su parte, intentan diseñar su propio concepto dirigido básicamente a la incriminación de determinados grupos u organizaciones. Las declaraciones de Mr. Jeremy Greenstock, embajador británico ante Naciones Unidas, reflejan, si bien no la realidad jurídica, al menos los lineamientos político criminales que se observan en este momento: "Lo que parece, huele y mata como terrorismo, es terrorismo" 6 .

Llama la atención, y en esto coincido con otros autores ${ }^{7}$, en la omisión en la Convención del terrorismo de Estado. Lo que se incrimina, siguiendo la tendencia político criminal postatentados de 11 de septiembre de 2001, son las conductas delictivas llevadas a cabo por grupos u organizaciones. El reciente instrumento internacional in comento desconoce absolutamente la violencia política, ilegítima e ilegal que constituye el terrorismo de Estado. En él, el aparato estatal ampara directa o indirectamente el uso de la violencia para dar continuidad a su proyecto político, pero por medios extralegales. Así concebido puede tener lugar tanto en los gobiernos de facto como en los sistemas democráticos.

La doctrina no ha logrado un acuerdo en torno a si en estos últimos puede o no existir terrorismo de Estado, es evidente que ningún Estado reconoce que ejerce o protege actos de terrorismo. No obstante no puede desconocerse históricamente que en más de una ocasión se ha amparado el ejercicio de una violencia que no se corresponde con los mandatos constitucionales (caso Operación Cóndor en Chile, caso GAL en España, caso de la guerra de Argel en Francia, caso de los paramilitares en Colombia y Perú).

Hay quienes niegan la posibilidad de sanción al terrorismo de Estado en el campo del derecho penal interno, indicando que si la validez del ordenamiento jurídico reposa en el propio Estado, el uso de la fuerza por su parte siempre sería legítimo ${ }^{8}$.

En mi opinión, concordando con otros autores ${ }^{9}$, si la negación del terrorismo de Estado se erige sobre la base de una utilización legítima de la violencia por parte de las instituciones

El Pais, domingo 7 de octubre de 2001,p. 10.

Teitelbaum, Alejandro. "Acerca del proyecto de Convención Interamericana contra el terrorismo", en www. cejil.org., mayo 2002.

Alejandro Teitelbaum es representante permanente de la Asociación Americana de Juristas ante los organismos de Ginebra.

8 Lamarca. Pérez, Carmen. Tratamicnto Jurídico del terrorismo, Centro de Publicaciones del Ministerio de Justicia, Secretaría General Técnica, Madrid, 1985, p. 33. En la misma opinión, Nestre Delgado, Esteban, Delincuencia terrorista y Audiencia Nacional, Madrid, Ministerio de Justicia, Servicio de Publicaciones, 1987, p. 31

9 Garcia Arán, M.; Ferré Olivé, J.C.; Hormazábal Malaree, H.; López Garrido, D.; Serrano Piedecasas, J.R. Contra la Impunidad, Dictamen auspiciado por la Federación de Asociaciones de Juristas progresistas sobre la persecución por los tribunales 
estatales, no puede pensarse que esta fuerza pueda ser usada a la vez legítima e ilegítimamente. La fuerza se utiliza ilegítimamente cuando funcionarios del Estado, con nexos oficiales (reconocidos o no), realizan conductas que atentan contra los derechos humanos y al margen de la legalidad vigente, con la finalidad de neutralizar o derechamente eliminar a las organizaciones terroristas.

Más allá de este debate, que ya parece estéril, lo que interesa es determinar si desde el plano jurídico positivo puede castigarse a título de terrorismo este tipo de conductas. Y en esto coincido con quienes niegan la imagen del Estado terrorista; es perfectamente posible que así sea cuando los hechos cometidos pudieran subsumirse en los tipos penales que cada legislación establece ${ }^{10} \cdot ¿$ Que ello implica reconocer que en un Estado democrático sus agentes han ejercido actos de terrorismo? No veo mayor problema, porque un Estado, si quiere alcanzar el ideal democrático, tiene que garantizar su propia abstersión interna y, en este sentido, propender a la igualitaria aplicación de la legislación en contra de quienes cometen actos de terrorismo.

Y si de acuerdo a estos criterios es perfectamente posible castigar a nivel interno las conductas terroristas que provienen del aparato estatal, con mayor razón es posible concebir que el terrorismo de Estado pueda ser castigado por normas internacionales, ya que éstas están diseñadas especialmente para castigar las violaciones a los derechos humanos por parte de los Estados. De ahí que resulte, a lo menos "curioso", si no tendencioso, que la Convención in comento se ocupe sólo de lo que se conoce como "terrorismo insurgente", esto es, aquel que nace con el objetivo de oponerse a un sistema político, económico y social determinado.

La CICT no define lo que entiende por terrorismo, se limita a enumerar en el art. 2 cuáles delitos, de los contenidos en diversos instrumentos internacionales, serán considerados delitos de terrorismo a efectos de la Convención, a saber:

- Convención para la Represión del Apoderamiento Ilícito de Aeronaves (La Haya, 1970), Convención para la Represión de Actos Ilícitos contra la Seguridad de la Aviación Civil (Montreal, 1971);

- Convenio sobre la Prevención y el Castigo de Delitos contra Personas Internacionalmente Protegidas, inclusive los Agentes Diplomáticos (AG de las NU, 14-12-1973;

- Convenio Internacional contra la Toma de Rehenes (AG de NU el 17-12-1979); Convención sobre la Protección Física de los Materiales Nucleares (Viena, 3-3-1987);

- Protocolo para la Represión de Actos Ilícitos deViolencia en los Aeropuertos que Prestan Servicios a la Aviación Civil Internacional, Complementaria del Convenio para la Represión de Actos Ilícitos Contra la Seguridad de la Aviación Civil (Montreal, 24-2-1988);

- Convenio para la Represión de Actos Ilícitos contra la Seguridad de la Navegación Marítima (Roma, 1988); Protocolo para la Represión de Actos Ilícitos contra la Seguridad de las Plataformas Fijas Emplazadas en la Plataforma Continental (Roma, 1988);

españoles de los crimenes contra la humanidad cometidos por las dictaduras chilena y argentina, Gráficas Alberdi, S.A. Octubre de 1998, p. 49. También en AAVV. Crimen internacional y jurisdición universal. El caso Pinochet, coord. por Mercedes Garcia Arán y Diego López Garrido, Edit. Tirant lo Blanch, 2000, p. 134.

10 En esta opinión, Lamarca, Carmen. "Sobre el concepto de terrorismo (A propósito del caso Amedo)". Anuario de Derecho Penal y Ciencias Penales, España 1993, pp. 541-542. 
- Convenio internacional para la Represión de los Atentados Terroristas Cometidos con Bombas (AG de NU, 15-12-1997);

- Convenio Internacional para la Represión de la Financiación del Terrorismo (AG de NU, 9-12-1999).

Con ello se excluye la posibilidad de concebir a los delitos de terrorismo como delitos autónomos, categoría que podría servir a los efectos de dar una mejor protección al objeto de tutela penal. Coincido con quienes estiman que el bien jurídico protegido en los delitos de terrorismo no es otro que el ordenamiento constitucional democrático ${ }^{11}$. Afirmación que sostengo tomando como criterio de valoración del contenido material del bien jurídico a los derechos humanos, en cuanto necesidades humanas, y en definitiva criterio legitimador del poder político ${ }^{12}$. Se trata de conductas que, elevadas a la categoría de delitos, tienen un contenido específico de lo injusto que excede al de los delitos comunes, lo que justifica su incriminación como delitos de nomen iuris propio $^{13}$.

Como se decía, la CICT opta por remitirse a los instrumentos internacionales ya mencionados, pero cayendo en contradicciones, como sagazmente lo ha advertido parte de la doctrina ${ }^{14}$, dando la impresión de que adopta un enfoque sectorial para definir el terrorismo, en circunstancias que en gran parte de su articulado se refiere a "terrorismo" y "terroristas" como si el terrorismo estuviera tipificado como delito autónomo.

Los errores de la técnica legislativa dan origen a un concepto de terrorismo difuso, conducente a tipos penales abiertos, reñidos con el principio de legalidad, y al mismo tiempo abre una puerta ancha a la analogía en materia penal. En definitiva, lo que es terrorismo será definido por cada Estado, posibilitando la aplicación arbitraria de la convención.Y más aun, posibilitando la incriminación de conductas de violencia espontánea o social, que nada tienen que ver con el terrorismo. Por esta vía podría ser castigado a título de terrorismo cualquier tipo de manifestaciones de disidencia, política o no, dando paso a una verdadera criminalización de los movimientos sociales.

Por otra parte, la inconcreción del concepto de terrorismo se convierte en un factor criminógeno favorable a violaciones a los derechos humanos, como las ocurridas en Guantánamo, y a infracciones al debido proceso legal, entre otros. E implicará asimismo la inclusión automática en la categoría de terroristas de cualquier grupo armado de la disidencia política ${ }^{15}$.

1.a. El trasfondo de la estrategia de ataque a las bases económicas financieras del terrorismo

Como he señalado en otro lugar ${ }^{16}$, la destrucción de las bases económicas y financieras del terrorismo nace a partir de una consideración errada por parte de los países europeos, y que

11 En esta opinión Lamarca, C. "Sobre el concepto de terrorismo...", 1993, la misma, Tratamiento Jurídico del Terrorismo..., 1985. García Rivas, Nicolás. La rebelión militar en el derecho penal, Edics. Universidad de Castilla La Mancha, pp. 117-141.

Villegas Díaz, Myrna. Terrorismo: Un problema de Estado..., 2001, Vol. II, pp. 590-596, 609-614.

Villegas Díaz, Myrna. Terrorismo: Un problema de Estado.., 2001, Vol. II, p. 1008.

Ampliamente, Teitelbaum, Alejandro, "Acerca del proyecto de Convenciön futcramericana..., 2002.

En esto coincido plenamente con el autor citado anteriormente.

Villegas Diaz, Myrna. Terrorismo: Un problema de Estado, 2001, Vol. 1, p. 367, pp. 259 y ss. 
tiende a exportarse cada vez más a nuestros países; y que es estimar que el terrorismo es una forma de crimen organizado, como el narcotráfico, la trata de blancas, y en general la gran criminalidad económica. Da cuenta de ello el art. 6 de la CICT que hace equivalentes a los delitos contenidos en su art. 2 los delitos determinantes en el lavado de dinero.

Esto significa que las figuras contenidas en los instrumentos internacionales señalados en el art. 2, y que en teoría nos dan el concepto de terrorismo, son equiparables a delitos determinantes del lavado de dinero, con lo que se está otorgando al terrorismo el mismo tratamiento jurídico que para la criminalidad organizada.

Terrorismo y crimen organizado no son equiparables porque existen diferencias de carácter teleológico y operacional. En cuanto a lo primero, el terrorismo tiene una finalidad política, en cambio el crimen organizado tiene una finalidad lucrativa. De ahí se sigue que cuando el terrorismo realiza actos delictivos que son propios del crimen organizado, el fin de lucro que persigue tiene un objetivo concreto: financiar la organización para que ésta alcance su objetivo político, ya que sin estructura el terrorismo no puede desarrollarse. En cambio las conductas del crimen organizado tienen por finalidad única este lucro.

En cuanto a lo segundo, diferencia operacional, porque el terrorismo es consciente de que necesita comunicar socialmente su mensaje, por tanto, reclama la publicidad de sus actos, tanto para conseguir apoyo popular como para destruir voluntades amedrentando. En cambio la criminalidad organizada reclama el silencio y el encubrimiento de sus actos ${ }^{17}$.

En consecuencia, el terrorismo no puede equipararse en su tratamiento a tales desviaciones sociales, porque si bien se estructura como organizaciones criminales, que forman redes internacionales, y se financian a través de actividades delictivas propias de la criminalidad económica, hay que resaltar que la característica esencial del terrorismo es el atentar contra los derechos humanos teniendo una finalidad política.

De ahí que la lucha contra el terrorismo requiera de una sociedad libre y democrática, en la que los canales de participación se encuentran abiertos, y el pleno respeto a las normas de derecho internacional de los derechos humanos y del derecho internacional humanitario.

\section{II.2. La concreción de la estrategia de ataque a las bases económicas y financieras del terrorismo}

Dentro de las medidas que establece la CICT para prevenir, combatir y erradicar el financiamiento del terrorismo, el artículo 4 ordena a los Estados a establecer "un régimen jurídico y administrativo para prevenir, combatir y erradicar la financiación del terrorismo y para lograr una cooperación internacional efectiva al respecto".

\section{Régimen jurídico y administrativo contra el financiamiento del terrorismo}

Esta normativa incluye en el art. 4.1.a):

"Un amplio régimen interno normativo y de supervisión para los bancos, otras instituciones financieras y otras entidades consideradas particularmente susceptibles de ser utilizadas

17 Idem. 
para financiar actividades terroristas. Este régimen destacará los requisitos relativos a la identificación del cliente, conservación de registros y comunicación de transacciones sospechosas e inusuales".

El precepto viene a ampliar el control de la actividad económica de toda clase de personas. En primer lugar, se habla de "otras entidades consideradas particularmente vulnerables de ser utilizadas para financiar actividades terroristas", de manera amplia, violentando el principio de legalidad. La calificación de tales entidades corresponde, en rigor, a la autoridad administrativa (policial), que es la encargada de la investigación de las actividades terroristas. El que dicha medida quede sujeta o no al control judicial dependerá de la normativa interna que cada Estado se dicte. Con ello se amplían las facultades a la autoridad administrativa, a riesgo de calificaciones arbitrarias.

Por otra parte, se vulnera el derecho a la intimidad, ya que se ordena mantener registros de identificación de clientes, conservarlos y comunicar transacciones "sospechosas". Según se desprende, cualquier persona, y sin conocimiento, queda registrada en una lista, y sujeta a observación por parte de la autoridad administrativa.

$\mathrm{El}$ art. 4.1.c) ordena a los Estados a crear una "unidad de inteligencia financiera". Su objeto es servir como centro nacional para la recopilación, análisis y difusión de información relevante sobre el lavado de dinero y financiación del terrorismo. Con ello se están traspolando los criterios de salvaguarda de la seguridad interior del Estado al campo privado, porque la unidad mencionada no será sino un eslabón más dentro de la cadena policial de los organismos de inteligencia encargados de reprimir la actividad terrorista.

El art. 5 se refiere al embargo y decomiso de fondos u otros bienes, ordenando a los Estados a adoptar las medidas necesarias para "identificar, congelar, embargar y, en su caso, decomiso de los fondos u otros bienes que constituyan el producto de la comisión o tengan como propósito financiar o hayan facilitado o financiado la comisión de cualquiera de los delitos establecidos en los instrumentos internacionales enumerados en el art. 2 de esta Convención".

Ello denota un adelantamiento exagerado de la barrera de protección penal ya que no sólo los fondos o bienes que hayan sido producto de la actividad terrorista pueden ser afectados, sino también aquellos que no han sido efectivamente utilizados o producto de la actividad terrorista. Basta que tengan como propósito financiar la comisión de actos de terrorismo.

Estas medidas se aplicarán a los delitos cometidos en la jurisdicción del Estado parte, tanto dentro como fuera de ella (extraterritorialidad). La extraterritorialidad se manifiesta también en el art. siguiente (art. 6) cuando señala que los delitos determinantes del lavado de dinero incluirán aquellos cometidos tanto dentro como fuera de la jurisdicción del Estado parte.

\section{Cooperación en el ámbito fronterizo (arts. 7, 8, y 9)}

Las medidas que se adoptan en este campo tienden a ampliar el control fronterizo y aduanero para prevenir la circulación de terroristas, el tráfico de armas y en general otros materiales destinados a apoyar la actividad terrorista. Se deja expresa constancia que tales medidas se llevarán a cabo "sin perjuicio de los compromisos internacionales aplicables al libre movimiento de personas y facilitación del comercio". 
El que puedan adoptarse tales medidas independientemente de lo dispuesto por los compromisos internacionales señalados, implica una severa restricción a la libre circulación de personas, derecho reconocido en la normativa internacional y nacional.

\section{3. "Traslado de personas bajo custodia".}

Reglamentado en el art. 10 el citado "traslado" no viene a constituir sino una verdadera, aunque sui géneris, extradición automática.

$\mathrm{El}$ art. 10 establece que una persona detenida o cumpliendo condena en el territorio de un Estado parte puede ser "trasladada" al territorio de otro Estado parte cuando éste lo solicitare a efectos de "prestar testimonio o de identificación o para que ayude a obtener pruebas necesarias para la investigación o enjuiciamiento de delitos de terrorismo".

El traslado sólo puede hacerse si la persona ha prestado libremente su consentimiento, cuando esté informada, cuando ambos Estados estén de acuerdo y con sujeción a las condiciones que ellos consideren apropiada.

No puede comprenderse dónde queda la voluntariedad de la persona en la prestación del consentimiento si una vez que ambos Estados están de acuerdo, y puestas las condiciones que estimen convenientes, puede ella ser trasladada. Tal parece que el consentimiento se presume, o al menos que ha sido forzado, toda vez que no existe norma alguna que prevea la falta de consentimiento en términos de dejar claramente establecido que si no existe la aquiescencia del detenido o condenado, éste no puede ser trasladado.

Ahora bien, el Estado al que sea trasladada la persona está "autorizado y obligado" a mantenerla detenida, salvo que el Estado desde el cual fue trasladada solicite o autorice otra cosa. Esto significa que una persona podría perfectamente quedar en libertad, o sujeto a alguna medida de vigilancia. No puede entenderse, dentro de la lógica que se aplica en la CICT, cómo se garantizaría entonces que una persona no quebrante la privación de libertad si es que está detenida, o la condena en su caso. A menos que se le dejare en libertad para someterla a vigilancia, sin su conocimiento, a objeto de pesquisar la actividad terrorista. Con ello la persona pasaría a ser un mero instrumento -que no individuo- en manos del Estado en la lucha contra el terrorismo, con lo que se violenta el principio básico de las sociedades contemporáneas: el respeto a la dignidad humana, al hombre en cuanto individuo.

Se señala, por otra parte, que el Estado al que sea trasladada la persona tiene la obligación de devolverla a la custodia del Estado desde el que fue trasladada según convengan de antemano o las autoridades competentes de ambos. De acuerdo a ello, y siguiendo las amplias prerrogativas que en virtud de la norma tienen los Estados, no existe un límite en el plazo del traslado, pudiendo transformarse en ese caso el traslado en una verdadera pena anticipada en el caso del detenido.Y la prueba está en que se tendrá en cuenta el tiempo de detención en ese Estado, a efectos del cómputo de la pena. Se vulnera el principio a la presunción de inocencia.

Por último, se señala que "el Estado al que sea trasladada la persona no podrá exigir al Estado desde el que fue trasladada que inicie procedimientos de extradición para su devolución" y que "dicha persona, cualquiera sea su nacionalidad, no será procesada, detenida ni sometida a ninguna otra restricción de su libertad personal en el territorio del Estado al que sea trasladada en relación con actos o condenas anteriores a su salida del territorio del Estado desde el que fue trasladada". 
Pareciera que se quiere dejar en claro que por este medio no se abre una puerta a la extradición. No obstante, el traslado, según se ha señalado, tiene todos los ribetes de esta figura, con la única e insuficiente limitación de que el Estado al que sea trasladada la persona está obligado a devolverla al Estado desde el que fue trasladado.

\section{Inaplicabilidad de la excepción por delito político}

El art. 11 contempla la ya tradicional en los instrumentos internacionales, cláusula belga o del atentado, y que consiste en negar el carácter de infracción política a hechos de terrorismo. Así, los delitos enumerados en los instrumentos internacionales que contempla el art. 2 de la CICT no serán considerados delito político o delito conexo con un delito político o un delito inspirado por motivos políticos. Luego, la solicitud de extradición o de asistencia jurídica mutua no podrá denegarse por la sola razón de que se relaciona con este tipo de infracciones.

La delincuencia política, entendida primero como ataque al jefe de gobierno, y más tarde como ataque a la organización del Estado, se ha manifestado de diversas formas a lo largo de la historia. Su importancia radica en un tratamiento favorable a quienes lo cometen, el que se manifiesta ya en la negativa a extraditar a sus autores cuando éstos se refugian en un Estado distinto al que lo cometen y en el otorgamiento de asilo político.

La distinción entre delitos de terrorismo y delitos políticos supone una aproximación al concepto de estos últimos ${ }^{18}$. La valoración de una conducta como un delito político implica una decisión de carácter político, que depende del contexto histórico en el que se comete. Así, por ejemplo, lo que para un Estado autoritario es delito de terrorismo, para un Estado democrático es delito político. Como decía Carrara, la historia del delito político es más política que jurídica, ya que esta infracción "no viene a definirse por verdades filosóficas, sino más bien por el predominio de los partidos $y$ de las fuerzas, por la suerte de una batalla"19.

En definitiva, serán los criterios políticos de cada Estado los que determinarán que hechos constituyen delitos políticos y cuáles delitos de terrorismo. Criterios que en muchos casos atienden a factores de conveniencia u oportunidad, como, por ejemplo, las circunstancias por las que atraviesan las relaciones diplomáticas entre cada Estado ${ }^{20}$.

De ahí que el concepto de delito político tenga un carácter relativo y pendular ya que depende de las concepciones políticas imperantes en un determinado momento, lo que ha impedido un aunamiento de criterios que permitan arribar a una definición en el plano

18 Ella surge en el Estado liberal, cuando sectores de la burguesia se enfrentaron al absolutismo. Fue Provo Klutt el primero en acuñar la denominación "delito político" con el objeto de darle un tratamiento más favorable a este tipo de delincuencia. Jiménez de Asúa, Tratado de Derecho penal, T II, $3^{2}$ edición, Edit. Losada, Buenos Aires, 1964, pp. 982 y ss. El tratamiento más favorable encontraría su razón de ser en que el delincuente político al refugiarse en el territorio de otro Estado se aminora considerablemente la posibilidad de poner en peligro la estabilidad de su país de origen, y no constituye un riesgo para la estabilidad de aquel que lo recibe.

19 Carrara, Francisco. Prograna del curso de Derecho Criminal, Tomo VII. Trad. de la $11^{2}$ ed. italiana, Buenos Aires, 1948. p. 512.

20 Esto fue, en mi opinión, lo que determinó que hasta mediados de los ános 90 Francia se negara a extraditar a miembros de ETA, y lo que determinó en su momento a España a negar la extradición de miembros del FPMR chileno. 
jurídico ${ }^{21}$. Pero a pesar de este carácter fluctuante, en mi opinión, se advierten algunos elementos esenciales:

a) Ser un hecho ilícito tipificado como delito en el Estado en que se comete, o universalmente aceptado como tal.

b) La finalidad política en el autor, que debe revestir un doble carácter: de un lado, la finalidad de desestabilizar y deslegitimar un determinado régimen de gobierno, y de otro lado, la finalidad de obtener el poder político para proceder a la instauración de un régimen distinto, que proteja los derechos de la sociedad en su conjunto.

c) Ser cometido en el contexto de un régimen autoritario, o de democracias meramente formales.

d) En la forma de ejecución de los actos, respetar las normas internacionales relativas a la protección de los derechos humanos. No podrían considerarse delitos políticos, por ejemplo, los asesinatos masivos de población. En tal sentido, y en el caso de conflictos armados que adquieran el carácter de guerra civil, respetar las normas humanitarias de los conflictos.

Un problema que se advierte, y al que se refiere la CICT, es el de los delitos conexos, en concreto, los delitos comunes cometidos con una finalidad política y el problema de aquellos que atentan contra la organización del Estado con una finalidad no política.

En esto coincido con quienes estiman que ellos deben ser entendidos en sentido amplio $^{22}$. Esto implica que si, por ejemplo, encontrándonos en el contexto de un régimen autoritario se comete un atentado contra la propiedad a objeto de financiar la estructura de un grupo armado que está luchando por acabar con ese régimen, esta conducta debe ser considerada como un delito político.Y ello porque sería incoherente dar asilo político, considerando delincuente político a quien, por ejemplo, mata o lesiona al jefe de ese gobierno, y negar esta categoría, y por ende, extraditar, a quien ha cometido un mero atentado contra la propiedad. Existiría una contradicción con el principio de lesividad.

No obstante hay un límite: el respeto a los derechos humanos fundamentales. De ahí que no pudieran ser considerados delitos políticos aquellas conductas que, en un sistema democrático material, atacan bienes jurídicos de la mayor importancia: vida, integridad fisica y salud de las personas.

En América Latina, al alero de estas dificultades, tradicionalmente se deja la incriminación de la conducta como delito político al Estado asilante. De ello dan cuenta las Convenciones de Montevideo (1933 y 1939) en sus arts. 2 y 3 respectivamente, así como la Convención de Caracas (1954). Esto porque es evidente que el Estado que ha sido objeto del ataque por parte del sujeto que solicita el asilo siempre calificará la conducta como delito común ${ }^{23}$.

21 A pesar de esto la doctrina ha hecho esfuerzos por delimitar su concepto, lo que ha dado lugar a tres grandes teorías para establecer la noción de delito político distinguiéndolo de los delitos comunes: objetiva, subjetiva y mixta, ecléctica o dominante. A pesar de ellas, y especialmente del eclecticismo de estas últimas no ha sido posible llegar a un concepto unívoco del mismo. Ampliamente Villegas Díaz, Myrna. Terrorismo: Un problema de Estado..., 2001, Vol. I, pp. 186 y ss.

22 En esta opinión, Lamarca Pérez, Carmen, Tratamiento Jurídico del Terrórismo, 1985, pp. 70-71.

23 Teitelbaum, Alejandro. "Acerca del Proyecto de Convención Interamericana...", 2002. 
La CICT en sus arts. 12, 13 y 14 ha abandonado esta concepción, señalando a los Estados Partes, como regla general y obligatoria, el excluir las conductas incriminadas de la calificación de delitos políticos, delitos conexos o inspirados por motivos políticos. Así se priva al Estado asilante de cualquier interpretación favorable a quien solicita refugio o asilo político, el que será siempre considerado o catalogado como terrorista para todos los efectos legales, especialmente si consideramos que por la inconcreción del concepto de terrorismo puede aplicarse la analogía en materia penal ${ }^{24}$. A estos puntos me refiero a continuación.

\section{Denegación de la condición de refugiado y del asilo}

El art. 12 niega la condición de refugiado a cualquier sospechoso de haber cometido un delito tipificado en los instrumentos internacionales enumerados en el Artículo 2.

Ello implica, en primer lugar, un desconocimiento del principio de presunción de inocencia, porque la medida procede no en virtud de una sentencia ejecutoriada que haya condenado a un sujeto por delito de los contenidos en el art. 2, sino en virtud de "motivos fundados" respecto de la comisión de tales delitos.

En segundo lugar, vulnera el Estatuto Internacional de los Refugiados. De acuerdo a lo señalado por la Convención de 1951, quedan excluidas de la condición de refugiado, entre otras, aquellas personas a las que no se considera merecedoras de la protección internacional (art. 1.F).Y se consideran tales aquellos que han cometido delitos contra la paz, un delito de guerra o un delito contra la humanidad. En parte alguna menciona a aquellos que hubieren cometido delitos de terrorismo.

Los delitos de terrorismo implican el uso de la fuerza, la comisión de actos de violencia, no menos que los crímenes contra la paz, contra la humanidad y crímenes de guerra. De esta forma, la exclusión de la categoría de refugiado sólo se verificará en caso de que los hechos fueren constitutivos de estos tres últimos.

Por otra parte, debe reconocerse que los delitos de terrorismo se relacionan con actividades u opiniones políticas.Y la persecución por motivo de opiniones políticas es una causa de inclusión en la condición de refugiado (art. 1 A, 2 de la Convención de 1951). De esta forma notamos implícitamente la negación de dicha condición por opiniones políticas. Si antes podía reclamarse el refugio por opiniones políticas, hoy día, y a la luz de la CICT, bastaría con que la autoridad administrativa (policía) considerara que existen motivos fundados para creer que una persona ha cometido un delito de terrorismo, para negarle el beneficio.Y esos motivos fundados perfectamente podrían adquirirse sobre la base de la opinión política contraria a las políticas de la autoridad y sus métodos.

Todo esto conduce a concluir que hay una intromisión de la CICT en el Estatuto, pues invade su esfera de competencia al extender su campo de punición a conductas que no se encuentran regladas en él. Lo que se agrava si consideramos que la medida procede en caso de una persona sospechosa, es decir, potencialmente todas las personas.

24 Coincido en este punto plenamente con Alejandro Teitelbaum. 
El art. 13 deniega el asilo respecto de quienes existen motivos fundados de haber cometido delitos de terrorismo a efectos de la CICT.

Es probable que pueda comprenderse una denegación de asilo político. Aunque no es menos cierto que basta la mera sospecha de haber cometido delitos de terrorismo. Lo que no puede comprenderse es la denegación de refugiado sobre quien no ha sido condenado por tales delitos, sino un sujeto al que asiste la presunción de inocencia.

El Art. 14 parece establecer un resguardo en el sentido de que no se considera imposición de prestar asistencia jurídica mutua si el Estado Parte solicitado tiene razones fundadas para creer que la solicitud ha sido hecha con el fin de enjuiciar a una persona en razón de su raza, religión, nacionalidad, etnia, u opinión política, o si el cumplimiento de la solicitud causaría un perjuicio a la situación de la persona por cualesquiera razones. Se establece un límite a la intervención de los Estados, pero, a la vez, se les dota de un mayor poder para decidir respecto de la consideración del carácter terrorista de una determinada conducta, y no precisamente al Estado Asilante. Como se decía, la introducción de la analogía en materia penal abre la puerta para que cualquier persona pueda ser calificada como terrorista, y en consecuencia tratada como tal.

\section{Derechos humanos}

El Art. 15 de la CICT también quiere establecer un resguardo señalando que las medidas adoptadas por los Estados Partes deben llevarse a cabo con pleno respeto al estado de derecho, los derechos humanos y libertades fundamentales. Y que debe entenderse que nada de lo dispuesto en la presente Convención debe interpretarse en el sentido de menoscabar otros derechos y obligaciones de los Estados y de las personas conforme al derecho internacional, en particular la Carta de las Naciones Unidas, la Carta de la Organización de los Estados Americanos, el derecho internacional humanitario, el derecho internacional de los derechos humanos y el derecho internacional de los refugiados.

Luego, parece ser que se garantiza un trato justo a toda persona que se encuentre detenida o respecto de la cual se hayan adoptado medidas o sea encausada en virtud de lo señalado en la Convención y el derecho internacional.

Tales preceptos parecen carecer de sentido si consideramos que la Convención ya en su texto viola el derecho internacional de los refugiados, y además deja una puerta abierta a la instauración de un verdadero Estado policial a través de la implementación de medidas no bien delimitadas y aparentemente no sujetas a control jurisdiccional.

\section{Conclusiones}

Primera: La CICT ha sido el producto de la fuerza expansiva de la hipertrofia legislativa en torno al terrorismo tras los atentados de 11 de septiembre de 2001. Atentados que no son una señal de que el terrorismo ha aumentado, sino más, bien una señal de que Estados Unidos necesitaba del terrorismo para paliar su propia crisis económica y política, consiguiendo el 
apoyo de otras naciones, principalmente europeas, para dar una concreción jurídico penal a la globalización.

Segunda: El terrorismo incriminado en la CICT es el desarrollado por grupos u organizaciones. Omite cualquier referencia al terrorismo de Estado. No se proporciona un concepto de terrorismo, existiendo la necesidad de arribar al mismo por dos grandes razones, una de legislación interna y la otra de legislación internacional.

En la legislación interna, es necesario limitar el ámbito de aplicación de la ley penal a conductas auténticamente terroristas, adecuándose al programa penal de la Constitución.

En la legislación internacional, es preciso distinguirlos de los delitos políticos para privarles su tratamiento benéfico, y de la criminalidad organizada para evitar que la internacionalización de la emergencia penal se materialice en los ordenamientos penales nacionales vaciándoles de los principios garantistas.

Tercera: La normativa internacional hace equiparables en su tratamiento los delitos de terrorismo con los delitos determinantes en el lavado de dinero. Es decir, otorga al terrorismo el tratamiento típico de la criminalidad organizada, sin considerar las diferencias teleológicas y operacionales que entre ellos existen. El terrorismo se caracteriza no sólo por la organización criminal, sino esencialmente por atentar contra los derechos humanos teniendo una finalidad política. De ahí que la legitimación de la lucha contra el terrorismo requiera de una democracia material.

Cuarta: En la necesidad de dar una respuesta rápida y eficaz ante la opinión pública, los Estados se unen para castigar al terrorismo desde la misma perspectiva que lo han hecho países europeos y Estados Unidos, sin entrar a considerar la identidad propia de nuestro continente, y de las formas que en ella adquiere la actividad terrorista. En América Latina las causas del terrorismo son fundamentalmente económicas y sociales, a diferencia del terrorismo que opera en Europa y en Oriente Medio.

En esta lucha, a toda costa contra el terrorismo, se violentan principios básicos en los Estados democráticos, como el de legalidad, seguridad jurídica, dignidad de la persona, presunción de inocencia.Y, más grave aún, se vulnera la normativa internacional desde que el propio texto de la CICT contradice lo señalado por la normativa internacional de refugiados y asilados políticos.

Quinta: Existe pues una involución en el sistema penal de garantías que no hace sino reflejar la verdadera esquizofrenia penal ante la cual nos encontramos: de un lado, códigos penales internos, legislación interna en general, que pugna por ser cada vez más garantista.Y de otro lado, una normativa internacional que pugna cada vez más por intervenir en las legislaciones nacionales rediseñando el ordenamiento jurídico, con un carácter claramente emergencista, mediante la alteración de normas comunes, pero sobre todo mediante la alteración de la normativa relativa a los derechos humanos, como lo es el refugio y el asilo político. 


\section{Bibliografia}

AA.VV. Crimen internacional y jurisdicción universal. El caso Pinochet, coord. por Mercedes García Arán y Diego López Garrido, Edit. Tirant Lo Blanch, 2000.

Carrara, Francisco. Programa del curso de Derecho Criminal. Tomo VII.Trad. de la $11^{\mathrm{a}} \mathrm{ed}$. italiana, Buenos Aires, 1948.

García Arán, M.; Ferré Olivé, J.C.; Hormazábal Malaree, H.; López Garrido, D.; Serrano Piedecasas, J.R. Contra la Impunidad (Dictamen auspiciado por la Federación de Asociaciones de Juristas progresistas sobre la persecución por los tribunales españoles de los crímenes contra la humanidad cometidos por las dictaduras chilena y argentina), Gráficas Alberdi, S.A., octubre de 1998.

García Rivas, Nicolás. La rebelión militar en el derecho penal, Edics. Universidad de Castilla La Mancha, 1990.

Jiménez de Asúa. Tratado de Derecho Penal, T. II, 3ª edición, Edit. Losada, Buenos Aires, 1964.

Lamarca Pérez, Carmen. Tratamiento Jurídico del Terrorismo, Centro de Publicaciones del Ministerio de Justicia, Secretaría General Técnica, Madrid, 1985.

Lamarca, Carmen. "Sobre el concepto de terrorismo (A propósito del caso Amedo)", en Anuario de Derecho Penal y Ciencias Penales, España, 1993.

Mestre Delgado, Esteban, Delincuencia Terrorista y Audiencia Nacional, Madrid, Ministerio de Justicia, Servicio de Publicaciones, 1987.

Teitelbaum, Alejandro. "Acerca del proyecto de Convención Interamericana contra el terrorismo", en www. cejil.org., mayo 2002.

Villegas Díaz, Myrna. Terrorismo: Un problema de Estado. Tratamiento jurídico en la legislación comparada. Especial referencia a los delitos de terrorismo en las legislaciones de Chile y España. Tesis doctoral, Universidad de Salamanca, España, 2001. 


\section{ANEXO 1 \\ Convención Interamericana contra el Terrorismo}

Trigésimo Segundo Período Ordinario de Sesiones

OEA/Ser. p. 2 de junio de 2002

Bridgetown, Barbados

3 junio 2002

\section{RESOLUCION}

Convención Interamericana contra el Terrorismo. (Aprobada en la primera sesión plenaria celebrada el 3 de junio de 2002)

\section{LA ASAMBLEA GENERAL}

Reafirmando los principios y disposiciones contenidos en la Carta de la Organización de los Estados Americanos y la Carta de las Naciones Unidas;

Reconociendo la amenaza que el terrorismo representa para los valores democráticos y para la paz y la seguridad internacionales y que es causa de profunda preocupación para todos los Estados Miembros;

Convencida que la Carta de la Organización de los Estados Americanos y el derecho internacional constituyen el marco apropiado para fortalecer la cooperación hemisférica en la prevención, combate y eliminación del terrorismo en todas sus formas y manifestaciones;

TENIENDO EN CUENTA la resolución RC.23/RES.1/01 rev. 1 corr. 1 Fortalecimiento de la cooperación hemisférica para prevenir, combatir y eliminar el terrorismo de la Vigésima Tercera Reunión de Consulta de los Ministros de Relaciones Exteriores del 21 de septiembre del 2001, que encomendó al Consejo Permanente la elaboración de un Proyecto de Convención Interamericana contra el Terrorismo;

Recordando la Declaración de Lima para Prevenir, Combatir y Eliminar el Terrorismo y el Plan de Acción de Cooperación Hemisférica para Prevenir, Combatir y Eliminar el Terrorismo, adoptado en el marco de la Primera Conferencia Especializada Interamericana sobre Terrorismo en Lima, Perú, en abril de 1996, así como el Compromiso de Mar del Plata, adoptado en la Segunda Conferencia Especializada Interamericana sobre Terrorismo y el trabajo del Comité Interamericano contra el Terrorismo (CICTE);

Considerando que el terrorismo constituye un grave fenómeno delictivo que preocupa profundamente a todos los Estados Miembros, atenta contra la democracia, impide el goce de los derechos humanos y las libertades fundamentales, amenaza la seguridad de los Estados, desestabilizando y socavando las 
bases de la toda la sociedad, y afecta seriamente el desarrollo económico y social de los Estados de la región;

Teniendo presente que la Carta Democrática Interamericana reconoce el compromiso de los Estados Miembros de promover y defender la democracia representativa, y que ningún Estado democrático puede permanecer indiferente frente a la clara amenaza que el terrorismo representa para las instituciones y libertades democráticas;

Reafirmando que la lucha contra el terrorismo debe realizarse con pleno respeto al derecho nacional e internacional, a los derechos humanos y a las instituciones democráticas, para preservar el estado de derecho, las libertades y los valores democráticos en el Hemisferio, elementos indispensables para una exitosa lucha contra el terrorismo;

CONVENCIDA DE QUE la adopción, ratificación e implementación efectiva de la Convención Interamericana contra el Terrorismo contribuye al desarrollo progresivo y la codificación del derecho internacional;

Destacando la importancia de una acción eficaz para eliminar el suministro de fondos para el terrorismo, así como el desarrollo de una acción coordinada con entidades internacionales competentes en materia de lavado de dinero, en especial la Comisión Interamericana contra el Abuso de Drogas (CICAD);

Reconociendo la urgencia de fortalecer y establecer nuevas formas de cooperación regional contra el terrorismo con el objeto de erradicarlo; y

Reconociendo la importancia y actualidad del acervo jurídico intemacional existente en la lucha contra el terrorismo, tanto en los diez instrumentos internacionales considerados en el texto de la propia Convención Interamericana contra el Terrorismo, como en la Convención para Prevenir y Sancionar los Actos de Terrorismo Configurados en Delitos contra las Personas y la Extorsión Conexa Cuando Estos Tengan Trascendencia Internacional, adoptada por la propia Asamblea General el 2 de febrero de 1971; el Convenio sobre las infracciones y ciertos otros actos cometidos a bordo de aeronaves, adoptado en Tokio el 14 de septiembre de 1963; y el Convenio sobre la Marcación de Explosivos Plásticos para los Fines de Detección adoptado en Montreal el 1 de marzo de 1991,

Resuelve:

1. Adoptar la Convención Interamericana contra el Terrorismo, la cual se anexa a la presente resolución y abrirla a la firma de los Estados Miembros en esta fecha.

2. Instar a los Estados Miembros a ratificar la Convención a la brevedad posible de conformidad con sus procedimientos constitucionales.

3. Solicitar al Secretario General que presente un informe al Trigésimo tercer Período ordinario de sesiones de la Asamblea General sobre el progreso registrado hacia la entrada en vigor de la Convención. 


\section{Proyecto de Convención Interamericana contra el Terrorismo.}

Los Estados Parte en la presente Convención,

TENIENDO PRESENTE los propósitos y principios de la Carta de la Organización de los Estados Americanos y de la Carta de las Naciones Unidas;

CONSIDERANDO que el terrorismo constituye una grave amenaza para los valores democráticos y para la paz y la seguridad internacionales y es causa de profunda preocupación para todos los Estados Miembros;

REAFIRMANDO la necesidad de adoptar en el sistema interamerícano medidas eficaces para prevenir, sancionar y eliminar el terrorismo mediante la más amplia cooperación;

RECONOCIENDO que los graves daños económicos a los Estados que pueden resultar de actos terroristas son uno de los factores que subrayan la necesidad de la cooperación y la urgencia de los esfuerzos para erradicar el terrorismo;

REAFIRMANDO el compromiso de los Estados de prevenir, combatir, sancionar y eliminar el terrorismo; $y$

TENIENDO EN CUENTA la resolución RC.23/RES. 1/01 rev. 1 corr. 1 "Fortalecimiento de la cooperación hemisférica para prevenir, combatir y eliminar el terrorismo", adoptada en la Vigésima Tercera Reunión de Consulta de Ministros de Relaciones Exteriores,

\section{HAN ACORDADO LO SIGUIENTE:}

\section{Artículo 1}

Objeto $\gamma$ fines.

La presente Convención tiene como objeto prevenir, sancionar y eliminar el terrorismo. Para tal efecto, los Estados Parte se comprometen a adoptar las medidas necesarias y fortalecer la cooperación entre ellos, de acuerdo con lo establecido en esta Convención.

\section{Artículo 2}

Instrumentos internacionales aplicables.

1. Para los propósitos de esta Convención, se entiende por delitos aquellos establecidos en los instrumentos internacionales que se indican a continuación:

- a. Convenio para la represión del apoderamiento ilícito de aeronaves, firmado en La Haya el 16 de diciembre de 1970.

- b. Convenio para la represión de actos ilícitos contra la seguridad de la aviación civil, firmado en Montreal el 23 de septiembre de 1971. 
- c. Convención sobre la prevención y el castigo de delitos contra personas internacionalmente protegidas, inclusive los agentes diplomáticos, aprobada por la Asamblea General de las Naciones Unidas el 14 de diciembre de 1973.

- d. Convención Internacional contra la toma de rehenes, aprobada por la Asamblea General de las Naciones Unidas el 17 de diciembre de 1979.

- e. Convenio sobre la protección física de los materiales nucleares, firmado en Viena el 3 de marzo de 1980.

- f. Protocolo para la represión de actos ilícitos de violencia en los aeropuertos que prestan servicios a la aviación civil internacional, complementario del Convenio para la represión de actos ilícitos contra la seguridad de la aviación civil, firmado en Montreal el 24 de febrero de 1988.

- g. Convenio para la represión de actos ilícitos contra la seguridad de la navegación marítima, hecho en Roma el 10 de marzo de 1988.

- h. Protocolo para la represión de actos ilícitos contra la seguridad de las plataformas fijas emplazadas en la plataforma continental, hecho en Roma el 10 de marzo de 1988.

- i. Convenio Internacional para la represión de los atentados terroristas cometidos con bombas, aprobado por la Asamblea General de las Naciones Unidas el 15 de diciembre de 1997.

- j. Convenio Internacional para la represión de la financiación del terrorismo, aprobado por la Asamblea General de las Naciones Unidas el 9 de diciembre de 1999.

2. Al depositar su instrumento de ratificación a la presente Convención, el Estado que no sea parte de uno o más de los instrumentos internacionales enumerados en el párrafo 1 de este artículo podrá declarar que, en la aplicación de esta Convención a ese Estado Parte, ese instrumento no se considerará incluido en el referido párrafo. La declaración cesará en sus efectos cuando dicho instrumento entre en vigor para ese Estado Parte, el cual notificará al depositario de este hecho.

3. Cuando un Estado Parte deje de ser parte de uno de los instrumentos internacionales enumerados en el párrafo 1 de este artículo, podrá hacer una declaración con respecto a ese instrumento, tal como se dispone en el párrafo 2 de este artículo.

Artículo 3

Medidas internas.

Cada Estado Parte, de acuerdo con sus disposiciones constitucionales, se esforzará por ser parte de los instrumentos internacionales enumerados en el artículo 2 de los cuales aún no sea parte y por adoptar las medidas necesarias para la aplicación efectiva de los mismos, incluido el establecimiento en su legislación interna de penas a los delitos ahí contemplados.' 
Artículo 4

Medidas para prevenir, combatir y erradicar la financiación del terrorismo.

1. Cada Estado Parte, en la medida en que no lo haya hecho, deberá establecer un régimen jurídico y administrativo para prevenir, combatir y erradicar la financiación del terrorismo y para lograr una cooperación internacional efectiva al respecto, la cual deberá incluir:

- a. Un amplio régimen interno normativo y de supervisión para los bancos, otras instituciones financieras y otras entidades consideradas particularmente susceptibles de ser utilizadas para financiar actividades terroristas. Este régimen destacará los requisitos relativos a la identificación del cliente, conservación de registros y comunicación de transacciones sospechosas o inusuales.

- b. Medidas de detección y vigilancia de movimientos transfronterizos de dinero en efectivo, instrumentos negociables al portador y otros movimientos relevantes de valores. Estas medidas estarán sujetas a salvaguardas para garantizar el debido uso de la información y no deberán impedir el movimiento legítimo de capitales.

- c. Medidas que aseguren que las autoridades competentes dedicadas a combatir los delitos establecidos en los instrumentos internacionales enumerados en el artículo 2 tengan la capacidad de cooperar e intercambiar información en los niveles nacional e internacional, de conformidad con las condiciones prescritas en el derecho interno. Con ese fin, cada Estado Parte deberá establecer y mantener una unidad de inteligencia financiera que sirva como centro nacional para la recopilación, el análisis y la difusión de información relevante sobre lavado de dinero y financiación del terrorismo.

Cada Estado Parte deberá informar al Secretario General de la Organización de los Estados Americanos sobre la autoridad designada como su unidad de inteligencia financiera.

2. Para la aplicación del párrafo 1 del presente artículo, los Estados Parte utilizarán como lineamientos las recomendaciones desarrolladas por las entidades regionales o internacionales especializadas, en particular, el Grupo de Acción Financiera Internacional (GAFI) y, cuando sea apropiado, la Comisión Interamericana para el Control del Abuso de Drogas (CICAD), el Grupo de Acción Financiera del Caribe (GAFIC) y el Grupo de Acción Financiera de Sudamérica (GAFISUD).

\section{Artículo 5}

Embargo $y$ decomiso de fondos $u$ otros bienes.

1. Cada Estado Parte, de conformidad con los procedimientos establecidos en su legislación interna, adoptará las medidas necesarias para identificar, congelar, embargar y, en su caso, proceder al decomiso de los fondos $\mathrm{u}$ otros bienes que constituyan el producto de la comisión o tengan como propósito financiar o hayan facilitado o financiado la comisión de cualquiera de los delitos establecidos en los instrumentos internacionales enumerados en el artículo 2 de esta Convención.

2. Las medidas a que se refiere el párrafo 1 serán aplicabłes respecto de los delitos cometidos tanto dentro como fuera de la jurisdicción del Estado Parte. 
Artículo 6

Delitos determinantes del lavado de dinero.

1. Cada Estado Parte tomará las medidas necesarias para asegurar que su legislación penal referida al delito del lavado de dinero incluya como delitos determinantes del lavado de dinero los delitos establecidos en los instrumentos internacionales enumerados en el artículo 2 de esta Convención.

Los delitos determinantes de lavado de dinero a que se refiere el párrafo 1 incluirán aquellos cometidos tanto dentro como fuera de la judisdicción del Estado Parte.

Artículo 7

Cooperación en el ámbito fronterizo.

1. Los Estados Parte, de conformidad con sus respectivos regímenes jurídicos y administrativos internos, promoverán la cooperación y el intercambio de información con el objeto de mejorar las medidas de control fronterizo y aduanero para detectar y prevenir la circulación internacional de terroristas y el tráfico de armas u otros materiales destinados a apoyar actividades terroristas.

2. En este sentido, promoverán la cooperación y el intercambio de información para mejorar sus controles de emisión de los documentos de viaje e identidad y evitar su falsificación, alteración ilegal o utilización fraudulenta.

3. Dichas medidas se llevarán a cabo sin perjuicio de los compromisos internacionales aplicables al libre movimiento de personas y a la facilitación del comercio.

Artículo 8

Cooperación entre autoridades competentes para la aplicación de la ley.

Los Estados Parte colaborarán estrechamente, de acuerdo con sus respectivos ordenamientos legales y administrativos internos, a fin de fortalecer la efectiva aplicación de la ley y combatir los delitos establecidos en los instrumentos internacionales enumerados en el artículo 2. En este sentido, establecerán y mejorarán, de ser necesario, los canales de comunicación entre sus autoridades competentes a fin de facilitar el intercambio seguro y rápido de información sobre todos los aspectos de los delitos establecidos en los instrumentos internacionales enumerados en el artículo 2 de esta Convención.

Artículo 9

Asistencia jurídica mutua.

Los Estados Parte se prestarán mutuamente la más amplia y expedita asistencia jurídica posible con relación a la prevención, investigación y proceso de los delitos establecidos en los instrumentos internacionales enumerados en el artículo 2 y los procesos relacionados con éstos, de conformidad con los acuerdos internacionales aplicables en vigor. En ausencia de esos acuerdos, los Estados Parte se prestarán dicha asistencia de manera expedita de conformidad con su legislación interna. 
Artículo 10

Traslado de personas bajo custodia.

1. La persona que se encuentre detenida o cumpliendo una condena en el territorio de un Estado Parte y cuya presencia se solicite en otro Estado Parte para fines de prestar testimonio o de identificación o para que ayude a obtener pruebas necesarias para la investigación o el enjuiciamiento de los delitos establecidos en los instrumentos internacionales enumerados en el artículo 2 podrá ser trasladada si se cumplen las condiciones siguientes:

- a. La persona presta libremente su consentimiento, una vez informada, y

- b. Ambos Estados están de acuerdo, con sujeción a las condiciones que consideren apropiadas.

2. A los efectos del presente artículo:

- a. El Estado al que sea trasladada la persona estará autorizado y obligado a mantenerla detenida, salvo que el Estado desde el que fue trasladada solicite o autorice otra cosa.

- b. El Estado al que sea trasladada la persona cumplirá sin dilación su obligación de devolverla a la custodia del Estado desde el que fue trasladada según convengan de antemano o de otro modo las autoridades competentes de ambos Estados.

- c. El Estado al que sea trasladada la persona no podrá exigir al Estado desde el que fue trasladada que inicie procedimientos de extradición para su devolución.

- d. Se tendrá en cuenta el tiempo que haya permanecido detenida la persona en el Estado al que ha sido trasladada a los efectos de descontarlo de la pena que ha de cumplir en el Estado desde el que haya sido trasladada.

3. A menos que el Estado Parte desde el cual se ha de trasladar una persona de conformidad con el presente artículo esté de acuerdo, dicha persona, cualquiera sea su nacionalidad, no será procesada, detenida ni sometida a cualquier otra restricción de su libertad personal en el territorio del Estado al que sea trasladada en relación con actos o condenas anteriores a su salida del territorio del Estado desde el que fue trasladada.

\section{Artículo 11}

Inaplicabilidad de la excepción por delito político.

Para los propósitos de extradición o asistencia jurídica mutua, ninguno de los delitos establecidos en los instrumentos internacionales enumerados en el artículo 2 se considerará como delito político o delito conexo con un delito político o un delito inspirado por motivos políticos. En consecuencia, una solicitud de extradición o de asistencia jurídica mutua no podrá denegarse por la sola razón de que se relaciona con un delito político o con un delito conexo corr un delito político o un delito inspirado por motivos políticos. 
Artículo 12

Denegación de la condición de refugiado.

Cada Estado Parte adoptará las medidas que corresponda, de conformidad con las disposiciones pertinentes del derecho interno e internacional, para asegurar que la condición de refugiado no se reconozca a las personas respecto de las cuales haya motivos fundados para considerar que han cometido un delito establecido en los instrumentos internacionales enumerados en el artículo 2 de esta Convención.

\section{Artículo 13}

Denegación de asilo.

Cada Estado Parte adoptará las medidas que corresponda, de conformidad con las disposiciones pertinentes del derecho interno e internacional, a fin de asegurar que el asilo no se otorgue a las personas respecto de las cuales haya motivos fundados para considerar que han cometido un delito establecido en los instrumentos internacionales enumerados en el artículo 2 de esta Convención.

\section{Artículo 14}

No discriminación.

Ninguna de las disposiciones de la presente Convención será interpretada como la imposición de una obligación de proporcionar asistencia jurídica mutua si el Estado Parte requerido tiene razones fundadas para creer que la solicitud ha sido hecha con el fin de enjuiciar o castigar a una persona por motivos de raza, religión, nacionalidad, origen étnico u opinión política o si el cumplimiento de la solicitud causaría un perjuicio a la situación de esa persona por cualquiera de estas razones.

\section{Artículo 15}

\section{Derechos humanos.}

1. Las medidas adoptadas por los Estados Parte de conformidad con esta Convención se llevarán a cabo con pleno respeto al estado de derecho, los derechos humanos y las libertades fundamentales.

2. Nada de lo dispuesto en la presente Convención se interpretará en el sentido de que menoscaba otros derechos y obligaciones de los Estados y de las personas conforme al derecho internacional, en particular la Carta de las Naciones Unidas, la Carta de la Organización de los Estados Americanos, el derecho internacional humanitario, el derecho internacional de los derechos humanos y el derecho internacional de los refugiados.

3. A toda persona que se encuentre detenida o respecto de la cual se adopte cualquier medida o sea encausada con arreglo a la presente Convención se le garantizará un trato justo, incluido el goce de todos los derechos y garantías de conformidad con la legislación del Estado en cuyo territorio se encuentre y las disposiciones pertinentes del derecho internacional. 


\section{Artículo 16}

Capacitación.

1. Los Estados Parte promoverán programas de cooperación técnica y capacitación, a nivel nacional, bilateral, subregional y regional y en el marco de la Organización de los Estados Americanos, para fortalecer las instituciones nacionales encargadas del cumplimiento de las obligaciones emanadas de la presente Convención.

2. Asimismo, los Estados Parte promoverán, según corresponda, programas de cooperación técnica y de capacitación con otras organizaciones regionales e internacionales que realicen actividades vinculadas con los propósitos de la presente Convención.

\section{Artículo 17}

Cooperación a través de la Organización de los Estados Americanos.

Los Estados Parte propiciarán la más amplia cooperación en el ámbito de los órganos pertinentes de la Organización de los Estados Americanos, incluido el Comité Interamericano contra el Terrorismo (CICTE), en materias relacionadas con el objeto y los fines de esta Convención.

\section{Artículo 18}

\section{Consulta entre las Partes.}

1. Los Estados Parte celebrarán reuniones periódicas de consulta, según consideren oportuno, con miras a facilitar:

- a. La plena implementación de la presente Convención, incluida la consideración de asuntos de interés relacionados con ella identificados por los Estados Parte; y

- b. El intercambio de información y experiencias sobre formas y métodos efectivos para prevenir, detectar, investigar y sancionar el terrorismo.

2. El Secretario General convocará una reunión de consulta de los Estados Parte después de recibir el décimo instrumento de ratificación. Sin perjuicio de ello, los Estados Parte podrán realizar las consultas que consideren apropiadas.

3. Los Estados Parte podrán solicitar a los órganos pertinentes de la Organización de los Estados Americanos, incluido el CICTE, que faciliten las consultas referidas en los párrafos anteriores y preste otras formas de asistencia respecto de la aplicación de esta Convención.

Artículo 19

Ejercicio de jurisdicción.

Nada de lo dispuesto en la presente Convención facultará a un Estado Parte para ejercer su jurisdicción en el territorio de otro Estado Parte ni para realizar en él fưnciones que estén exclusivamente reservadas a las autoridades de ese otro Estado Parte por su derecho interno. 
Artículo 20

Depositario.

El instrumento original de la presente Convención, cuyos textos en español, francés, inglés y portugués son igualmente auténticos, será depositado en la Secretaría General de la Organización de los Estados Americanos.

Artículo 21

Firma y ratificación.

1. La presente Convención está abierta a la firma de todos los Estados Miembros de la Organización de los Estados Americanos.

2. Esta Convención está sujeta a ratificación por parte de los Estados signatarios de acuerdo con sus respectivos procedimientos constitucionales. Los instrumentos de ratificación serán depositados en la Secretaría General de la Organización de los Estados Americanos.

Artículo 22

Entrada en vigor.

1. La presente Convención entrará en vigor el trigésimo día a partir de la fecha en que haya sido depositado el sexto instrumento de ratificación de la Convención en la Secretaría General de la Organización de los Estados Americanos.

2. Para cada Estado que ratifique la Convención después de que se haya depositado el sexto instrumento de ratificación, la Convención entrará en vigor el trigésimo día a partir de la fecha en que tal Estado haya depositado el instrumento correspondiente.

Artículo 23

Denuncia.

1. Cualquier Estado Parte podrá denunciar la presente Convención mediante notificación escrita dirigida al Secretario General de la Organización de los Estados Americanos. La denuncia surtirá efecto un año después de la fecha en que la notificación haya sido recibida por el Secretario General de la Organización.

2. Dicha denuncia no afectará ninguna solicitud de información o de asistencia hecha durante el período de vigencia de la Convención para el Estado denunciante. 


\section{ANEXO 2}

\section{A-66: Convención Interamericana contra el Terrorismo}

ADOPTADO EN: Bridgetown, Barbados

FECHA. 06/03/2002

REUNIÓN:Trigésimo segundo periodo ordinario de sesiones de la Asamblea General de la OEA

ENTRADA EN VIGOR: Trigésimo día a partir de la fecha en que haya sido depositado el sexto instrumento de ratificación

DEPOSITARIO: Secretaría General de la OEA (instrumento original e instrumentos de ratificación)

INFORMACIÓN GENERAL DEL TRATADO:A-66

\begin{tabular}{|l|c|c|c|c|}
\hline Países Signatarios & Firma & Ratificación/Adhesión & Depósito & Información* \\
\hline Antigua y Barbuda & $06 / 03 / 2002$ & - & - & - \\
Argentina & $06 / 03 / 2002$ & - & - & - \\
Bahamas & $06 / 03 / 2002$ & - & - & - \\
Barbados & $06 / 03 / 2002$ & - & - & - \\
Belize & $06 / 03 / 2002$ & - & - & - \\
Bolivia & $06 / 03 / 2002$ & - & - & - \\
Brasil & $06 / 03 / 2002$ & - & - & - \\
Canadá & - & - & - & - \\
Chile & $06 / 03 / 2002$ & - & - & - \\
Colombia & $06 / 03 / 2002$ & - & - & - \\
Costa Rica & $06 / 03 / 2002$ & - & - & - \\
Dominica & - & - & - & - \\
Ecuador & $06 / 03 / 2002$ & - & - & - \\
El Salvador & $06 / 03 / 2002$ & - & - & - \\
Estados Unidos & $06 / 03 / 2002$ & - & - & - \\
Grenada & $06 / 03 / 2002$ & - & - & - \\
Guatemala & $06 / 03 / 2002$ & - & - & - \\
Guyana & $06 / 03 / 2002$ & - & - & - \\
Haití & $06 / 03 / 2002$ & - & - & - \\
Honduras & $06 / 03 / 2002$ & - & - & - \\
Jamaica & $06 / 03 / 2002$ & - & - & - \\
México & $06 / 03 / 2002$ & - & - & - \\
Nicaragua & $06 / 03 / 2002$ & $06 / 03 / 2002$ & - & - \\
Panamá & $06 / 03 / 2002$ & - & - & - \\
Paraguay & $06 / 03 / 2002$ & - & - & - \\
Perú & & - & - & - \\
\hline
\end{tabular}




\begin{tabular}{|l|c|c|c|c|}
\hline Países Signatarios & Firma & Ratificación/Adhesión & Depósito & Información ${ }^{*}$ \\
\hline República Dominicana & $07 / 03 / 2002$ & - & - & - \\
San Kits y Nevis & $06 / 03 / 2002$ & - & - & - \\
Santa Lucía & $06 / 03 / 2002$ & - & - & - \\
St.Vicente y Grenadines & $06 / 03 / 2002$ & - & - & - \\
Suriname & $06 / 03 / 2002$ & - & - & - \\
Trinidad y Tobago & - & - & - & - \\
Uruguay & $06 / 03 / 2002$ & - & - & - \\
Venezuela & $06 / 03 / 2002$ & - & & - \\
\hline
\end{tabular}

\section{* DECLARACIONES/RESERVAS/DENUNCIAS/RETIROS}

Ecuador: Declaración al momento de la firma: (3 de junio de 2002) al suscribirse la presente Convención, el Gobierno de Ecuador:

1. Deplora que los Estados Miembros no hayan podido llegar a un consenso sobre la tipificación de terrorismo y su calificación como crimen internacional de lesa humanidad.

2. Considera que, a pesar de los vacíos que adolece la Convención, puede ser un mecanismo eficaz para que los Estados Americanos continúen la lucha contra el crimen del terrorismo.

3. Expresa su convencimiento de que es necesario que los Estados comprometan su indeclinable voluntad política para aplicar estrictamente los principios y disposiciones de la Convención.

4. Declara que la suscripción de la presente Convención no entraña aceptación o aprobación de instrumentos internacionales de los que el Ecuador no es Parte. Por tanto, aplicará aquellos instrumentos de los que sea Parte o llegue a serlo.

México: Declaración Interpretativa al momento de la firma en relación con el artículo 16, párrafo 2: (3 de junio de 2002)

"Sin menoscabo de la determinación de México de combatir todos los actos, métodos y prácticas del terrorismo, mi Gobierno interpreta que el derecho de asilo queda comprendido en el derecho internacional de los derechos humanos a que se refiere el párrafo 2 del artículo 15 de esta Convención, toda vez que, tanto el artículo 14 de la Declaración Universal de los Derechos Humanos, como el artículo XXVII de la Declaración Americana de los Derechos y Deberes del Hombre, consagran el derecho de toda persona de buscar y recibir asilo en territorio extranjero.

En virtud de lo anterior, toda solicitud de cooperación que tenga como base la presente Convención, será decidida por mi Gobierno de conformidad con ésta, su legislación interna y otros instrumentos internacionales aplicables." 